\title{
A EPIDEMIA DO CÓLERA EM A MORTE EM VENEZA, DE THOMAS MANN'
}

\section{THE CHOLERA EPIDEMIC IN DEATH IN VENICE, BY THOMAS MANN}

\section{Denise Rocha}

RESUMO: O objetivo do estudo é mostrar a viagem externa e interna de Gustav Aschenbach, um escritor alemão, viúvo, famoso e rico, protagonista de $A$ morte em Veneza, de Thomas Mann, o qual vivenciou e ficcionalizou na novela, a epidemia do cólera, ocorrida na Itália, em 1911. Com partida de Munique, o autor segue até Veneza, a fim de descansar durante o verão. Hospedado no Grande Hotel dos Banhos, ele desenvolve um amor platônico pelo ideal da juventude e da beleza, personificada por Tadeus (Tadzio), que tinha 14 aos de idade. A análise da paisagem física e abstrata de Veneza, imersa na rápida propagação de uma enfermidade letal, que, inicialmente, foi ocultada dos turistas e atingiu mortalmente Aschenbach, será baseada nos conceitos de 'lugar concreto' e de 'espaço abstrato', de Tuan.

PALAVRAS-CHAVE: Literatura alemã. Thomas Mann. A morte em Veneza. Paisagem. Doença.

ABSTRACT: The objective of the study is to show the external and internal journey of Gustav Aschenbach, a famous and wealthy German writer, widower, protagonista of The Death in Venice, by Thomas Mann, who experienced and ficitonalized in the novel, the cholera epidemic, which occurred in Italy, in 1911. Departing from Munich, the autor goes to Venice, in order to rest during the summer. Stayed at the Grande Hotel dos Banhos, he develops a platonic love for the ideal of youth and beauty, personified by Tadeus (Tadzio), who was 14 years old. The analysis of the physical and abstract landscape of Venice, immersed in the rapid spread of a lethal disease, which was initially hidden from tourists and mortally affected Aschenbach, will be based on Tuan's concept of 'concret place' and 'abstract space'.

KEYWORDS: German Literature. Thomas Mann. Death in Venice. Landscape. Illnes.

\footnotetext{
${ }^{1}$ Artigo recebido em 30 de agosto de 2021 e aceito para publicação em 10 de outubro de 2021.

2 Pós-Graduação em Letras, Universidade Federal do Ceará. Profa. Dra. E-mail: rocha.denise57@ gmail.com. ORCID: https://orcid.org/0000-0003-3906-2957.
} 


\section{Introduçầo}

Vencedor do Prêmio Nobel da Literatura de 1929 pelo romance, Buddenbrooks: Decadência de uma família (1901), o alemão Thomas Mann (1875-1955) ${ }^{3}$ começou, a elaborar A morte em Veneza, em Bad Tölz, estância de água mineral, na qual ele e familiares costumavam passar as férias. (V.K., 2002, p. V10).

A escrita da novela ocorreu em 1911, ano no qual, Mann vivenciou, na referida cidade italiana, a epidemia do cólera, que provocou a morte de inúmeros nativos e turistas, e se tornou o leitmotiv da mencionada obra. Além de ter conhecido um menino polonês de 14 anos, Wladyslaw Baron Moes (Wladzio), que o inspirou a criar o perfil do protagonista menino. (BAHR, 1991, p. 42).

A narrativa, A morte em Veneza, aborda a trajetória de Gustav Aschenbach, um escritor viúvo de cerca de 50 anos de idade, famoso, rico e grisalho, que residia em Munique. Com bloqueio criativo, o protagonista partiu até Veneza, a fim de descansar durante o verão. Hospedado no Grande Hotel dos Banhos, na ilha Lido, o alemão desenvolve um amor platônico pelo ideal da juventude e da beleza, personificada por Tadeus (Tadzio), que ali estava com a mãe, três irmãs e uma governanta. Aschenbach observa, insistentemente, o menino belo, mas de aparência doentia, inclusive seguindo os passeios dele com a família, mas nunca lhe dirigiu a palavra.

Sentindo-se envelhecido, o alemão busca o barbeiro que tinge os seus cabelos e faz um tipo de maquiagem rejuvenescedora. O siroco, o vento quente e úmido, que abafava a cidade, começa a prejudicar a frágil saúde dele, que sem saber encontrava-se em uma zona de perigo, por causa das águas fétidas e contaminadas da lagoa e dos canais, que transmitiam uma enfermidade letal. Para não prejudicar o comércio, as autoridades evitavam alarmar a população sobre a epidemia, no entanto, um inglês informou sobre o mal latente ao escritor. Este, entretanto preferiu

${ }^{3}$ A ampla obra de Thomas Mann (1875-1955) abrange ensaios e narrativas: Contos: Caído (publicado em 1894), A vontade de felicidade, Desilusão e O pequeno Herr Friedemann (1896), Morte, O palhaço e O diletante (1897), Tobias Mindernickel (1898), O guarda roupa (1899), Luischen (1900), A criança prodígio (1903) etc. Novelas: Gladius Dei (1902), Tristan (1903), Tonio Kröger (1903), Morte em Veneza (1912), Um homem e seu cão (1918), Desordem e tristeza precoce (1925), Mário e o mágico (1930), José e seus irmãos (1936-1943), As cabeças transpostas (1940), As Tábuas da Lei (1944) e A narrativa enganosa (1954); e romances: Buddenbrooks (1901), Alteza Real (1909), A Montanha Mágica (1924), Doutor Faustus: A vida do compositor alemão Adrian Leverkühn narrada por um amigo (1947), O Santo Pecador (1951) e As confissões do impostor Felix Krull (1954). 
ficar para observar e seguir Tadzio nas dependências do hotel, na praia e em Veneza.

Anatol Rosenfeld, na obra Thomas Mann, menciona que "Aschenbach vê no jovem Tadzio o reflexo temporal da beleza eterna, do ideal sempre perseguido e de tal modo irresistivel na sua encarnação que se acha moralmente desarmado diante da imagem perfeita" (ROSENFELD, 1994, p. 183).

O objetivo do estudo, "A epidemia do cólera em A morte em Veneza (1911-1912), de Thomas Mann (1875-1955)", é mostrar a viagem externa e interna de Gustav Aschenbach, que estava em conflito com a escrita e com a velhice, e parte para Veneza, em estação de veraneio. A análise sobre a paisagem geográfica e sociocultural, física e abstrata, da cidade italiana, formada por inúmeros canais, uma laguna e proximidade com o mar Adriático, cujo volume de águas propicia a propagação da epidemia do cólera, que atingiu mortalmente o protagonista, será baseada nos conceitos de 'lugar concreto' e de 'espaço abstrato', de Tuan.

\section{A paisagem: 0 'lugar concreto' e 0 'espaço abstrato' (Yi-Fu Tuan)}

Na obra, Espaço e lugar: a perspectiva da experiência, Tuan vincula a natureza da experiência e da perspectiva experiencial: o lugar "é uma concreção de valor, embora não seja uma coisa valiosa, que possa ser facilmente manipulada ou levada de um lado para o outro; é um objeto no qual se pode morar, isso quer dizer que o lugar é um mundo de significado organizado" (TUAN, 2013, p. 22).

Na narrativa, Veneza é o lugar concreto, e as experiências de Aschenbach, as sensoriais e as simbólicas, que são dotadas de valor, estão vinculadas com a propagação da epidemia pelas águas e alimentos, bem como com a observação do menino Tadzio, que tinha o porte e a aparência clássica de uma estátua grega.

\section{Veneza e a epidemia de 1911}

Constituída por um grupo de pequenas ilhas e canais ligados por pontes, Veneza, capital de Veneto, localiza-se na pantanosa lagoa homônima, na região ao longo da costa entre as nascentes dos rios Po (sul) e Piave (nordeste), que desaguam no Mar 
Adriático. Nessa conhecida cidade histórica (VENEZA, s.d., p. 1), cuja Praça de São Marcos atrai turistas do mundo todo, destaca-se a Ilha Lido, centro turístico e estância balneária, localizada na entrada da Laguna de Veneza e na praia adriática, que tem uma sofisticada paisagem hoteleira: Hôtel P. Ortolanella, Alb. P. Laguna, Hôtel Villa Regina, Grand Hôtel Hungaria, Grand Hôtel Lido e Grand Hôtel des Bains (BAHR, 1991, p. 39), no qual se desenvolve a narrativa de Thomas Mann.

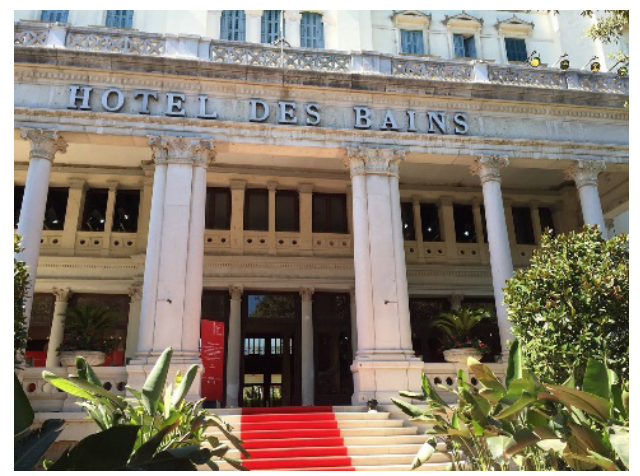

Fig. 1 - Hotel dos Banhos (Hotel des Bains), em Veneza

Desde o final de maio até 2 de junho de 1911, Mann, sua esposa Katia e o irmão dele, Heinrich, estavam em Veneza, quando o cólera asiático chegou. Nas anotações para elaboração da novela, que estão no Arquivo Thomas Mann de Zurique, há um recorte do jornal Münchner Neuesten Nachrichten, de 5 de setembro de 1911, sobre a epidemia, em Palermo que tinha 350.000 habitantes: 772 casos, 393 fatais (junho); 1132 casos, 307 fatais (julho), e 531 casos, 95 fatais (agosto). (BAHR, 1991, p. 109).

Em A morte em Veneza, um inglês informa o alemão, de forma didática, sobre a origem indiana da enfermidade, $\mathrm{o}$ alastramento europeu e a periculosidade na Itália:

Desde alguns anos, a cólera hindu havia demonstrado uma tendência a alastrar-se e emigrar. Originada dos pântanos quentes do delta do Ganges, aparecendo com o alento mefítico daquele exuberante-inútil mundo antediluviano e ilhas selvagens evitadas pelo homem em cujos espessos bambuzais espreitava o tigre, a epidemia desencadeara-se em todo o Indostão, contínua e extraordinariamente violenta alastrara-se 
para a China ao oeste, para o Afeganistão e a Pérsia ao leste e, seguindo as estradas principais do tráfego de caravanas, levara seus horrores até Astracã, e mesmo até Moscou. Mas, enquanto a Europa tremia de que por terra o fantasma pudesse fazer sua entrada, este fora desviado pelo mar por comerciantes navegadores sírios, aparecendo quase que ao mesmo tempo, em vários portos mediterrânicos, erguera sua cabeça em Toulon e Málaga, mostrara sua máscara muitas vezes em Palermo e Nápoles e pareceria não mais retroceder de toda a Calábria e Apúlia (MANN, 1979, p. 157).

A propagação do cólera asiático, ${ }^{4}$ segundo o turista inglês, tinha atingido Veneza, em maio: "os terríveis vibriões nos cadáveres esfalfados e negros de um tripulante de navio e uma quitandeira. Os casos foram ocultados. Mas, depois de uma semana, já havia dez, vinte, trinta deles, e em bairros diferentes". Fato é que um austríaco, que ali estivera, morrera em sua terra natal, com sintomas evidentes e "os primeiros boatos sobre a tribulação da cidade das lagunas apareceram nos jornais alemães". No entanto, "autoridades venezianas mandaram responder que as condições salutares da cidade nunca foram melhores, e tomaram as necessárias providências para o combate". (MANN, 1979, p. 157 e 158). A infecção, que atingia os alimentos, as verduras, o leite a as carnes, propagava-se pelo calor intenso que aquecia as águas da lagoa: "parecia mesmo que a epidemia sofrera uma nova animação de suas forças, como se a tenacidade e a fertilidade de seus bacilos se tivesse redobrado". Os sintomas eram terríveis:

\begin{abstract}
Casos de restabelecimento eram raros: oitenta de cem atingidos morriam, e isto de uma maneira horrível, pois o mal aparecia com extrema selvageria e muitas vezes mostrava aquela forma mais perigosa, que é chamada a "seca". Neste caso o corpo não conseguia eliminar a água segregada em quantidade das artérias. Dentro de poucas horas o doente secava e sufocava do sangue resistente como pez, sob câimbras e lamentos roucos. Feliz daquele cuja erupção se dava em forma de um profundo desmaio, como às
\end{abstract}

${ }^{4}$ A profunda pesquisa de Mann sobre o cholera asiatico também está documentada em suas anotações (BAHR, 1991, p. 95-100). 
vezes acontecia, depois de um leva mal-estar, do qual não acordava mais (MANN, 1979, p. 158).

No mês de junho, de acordo com o narrador das desgraças, a situação tinha se agravado e começaram "a encher, em silêncio, as barracas de isolamento do Ospedale Civico; nos dois orfanatos já não havia lugar e um tráfego horripilantemente ativo imperava entre o cais dos fundamentos novos e São Miguel, a ilha-cemitério". (MANN, 1979, p. 158). Apesar das tragédias, as autoridades ocultavam as informações. Esse cálculo financeiro é denunciado na novela de Mann.

\section{0 escritor alemăo: 0 sentimento da velhice}

Em relação à concepção da narrativa $A$ morte em Veneza, Thomas Mann explica, em carta de 6 de setembro de 1915, à Elisabeth Zimmer $(\mathrm{Br} \mathrm{l}, 123)$, que a sua intenção era escrever sobre o amor de um idoso por uma menina, baseado na vida de Goethe (MANN apud BAHR, 1991, p. 117), que aos 72 anos $^{5}$ tinha a intenção de se casar com uma adolescente. Porém, depois de sua estadia na cidade italiana, em 1911, o escritor tinha modificado o perfil dos personagens principais: um homem, que envelhecia, apaixonara-se pela beleza clássica de um menino.

Nesse mesmo ano, no dia 18 de maio, Mann, quando estava na Ilha Brioni, tinha sido informado sobre a morte, em Viena, do músico austríaco Gustav Mahler (1860-1911), que se tornou o modelo para a elaboração do protagonista Gustav Aschenbach. (MANN apud BAHR, 1991, p. 120). Na narrativa, a ação se desenvolve em Munique, Pula e Veneza, na qual o escritor passa cerca de quatro semanas em uma paisagem harmoniosa e saudável, que se transforma, aos poucos, em uma paisagem de pestilência e mortes.

O protagonista Aschenbach era "o poeta de todos aqueles que trabalhavam à margem do esgotamento, dos oprimidos, já aniquilados, ainda se mantendo de pé", além de "todos estes moralistas da produção, que ao menos, durante algum tempo, ganham os efeitos da grandeza pelo arrebatamento da vontade

5 Johann Wolfgang von Goethe (1749-1832) conheceu, no ano de 1821, em Marienbad, Ulrike von Levetzow de 17 anos. Ela recusou seu pedido de casamento (MORENO CLAROS, 2008, p. 1). 
e inteligente administração, apesar do físico franzino e de meios precários" (MANN, 1979, p. 97).

Com saúde fragilizada, aos 50 anos, o escritor, residente em Munique, viajou para Trieste, passando por Pula, e seguiu até Veneza, onde instalou-se no Hotel dos Banhos, na ilha do Lido, deslocando-se de barca, gôndola e vaporetto pelas águas da cidade: Canal de São Marcos, Ponte dos Suspiros, Hotel Excelsior, Ponte das Barcas, Catedral da Praça de São Marcos, Câmara Municipal, entre outros locais turísticos.

A paisagem sociocultural festiva para os visitantes ocultava a paisagem doentia crescente pela disseminação do cólera, que em distintos momentos é mencionada, negada ou confirmada: a repentina partida de hóspedes alemães e austríacos do Hotel dos Banhos; os cartazes impressos e afixados em esquinas municipais com advertências sobre o consumo de frutos do mar e de água do canal; a negação do gerente do hotel e a de um músico sobre o mal; e a confirmação do turista inglês.

O escritor, em crise literária, revela suas fragilidades de homem apolíneo que tem um encontro com um dionisíaco, "perfeitamente belo", Tadzio: "Seu rosto pálido e graciosamente fechado, circundado por cabelos cacheados, louros cor de mel, com o nariz reto, a boca suave, a expressão de seriedade divina, lembrava esculturas gregas dos mais nobres tempos e da mais pura perfeição" (MANN, 1979, p. 113).

Quase todas as manhãs, Aschenbach ia para a praia e sentava-se em uma cadeira espreguiçadeira, instalada em cabine individual. Com a máquina de escrever portátil, ele procurava elaborar uma obra, enquanto observava os turistas e, principalmente, o menino polonês. Certo dia, da janela, ao meio dia, o escritor, ao mirar o jovem que retornava da praia, foi invadido por um poderoso e desconhecido sentimento: "Tadzio, aí também está você de novo!". Porém, no mesmo instante: "sentiu como esta saudação negligente desfalecia e silenciava perante a verdade de seu coração - sentiu o entusiasmo de seu sangue, a alegria, a dor de sua alma, e reconheceu que por causa de Tadzio a despedida se tornara tão penosa para ele". (MANN, 1979, p. 130). Ele sentia certa premonição sobre a sua vida. 


\section{Siroco, o vento que espalhava o cólera}

$\mathrm{Na}$ quarta semana de prazer no Hotel dos Banhos, Aschenbach fez algumas "descobertas sinistras", como a repentina ausência do idioma alemão nas dependências hoteleiras. $O$ barbeiro, ao ser questionado sobre o motivo, contestou: "O senhor fica; o senhor não tem medo do mal", sem explicar o que seria tal perigo. (MANN, 1979, p. 143). Na mesma tarde, na Praça de São Marcos, o escritor percebeu: "um cheiro adocicado, oficial, que lembrava miséria, feridas e limpeza desconfiante", além de observar que em cartazes:

[...] a Câmara Municipal prevenia o povo de que, devido a certas doenças gástricas, normais, nesta temperatura, se abstivesse do consumo de ostras e conchas e da água dos canais. A natureza atenuante do edital era clara. Grupos de pessoas se ajuntavam silenciosos sobre pontes e praças; e o estranho estava entre eles, farejando e meditando (MANN, 1979, p. 144).

Assustado, ele perguntou sobre o "cheiro fatal" a um lojista, que respondeu ser "uma medida preventiva". Tratava-se de "Uma ordem de polícia, que temos de aprovar. Esta temperatura abate e o siroco não faz bem à saúde. Em resumo, o senhor compreende talvez uma precaução exagerada...". Na barca de retorno ao Lido, Aschenbach sentiu "o cheiro do remédio combatedor de germes" (MANN, 1979, p. 144 e 145). No hotel, ele constatou que os jornais estrangeiros e italianos nada noticiavam e teve "uma satisfação obscura", porque "esse grave segredo da cidade que se fundia com o seu próprio segredo e cuja preservação lhe dizia tanto. Pois ao apaixonado só preocupava que Tadzio talvez pudesse partir, e reconheceu, assustado, que não saberia mais viver, se tal acontecesse" (MANN, 1979, p. 145). Preocupado, o alemão:

[...] Aferrado a averiguar notícias novas e precisas sobre o estado e o progresso do mal, passava em revista os jornais do país nos cafés da cidade, porque há vários dias tinham desaparecido da mesa de leitura do hotel. Afirmações e desmentidos se revezavam. 0 número de casos de doenças, de mortes, se elevava a vinte, a quarenta, mesmo a cem e mais, e, logo de- 
pois, qualquer existência da epidemia, quando não desmentida categoricamente, era atribuída a casos isolados trazidos de fora. (MANN, 1979, p. 149)

Diante do panorama de negação local, o escritor tinha "uma satisfação bizarra em dirigir perguntas insidiosas aos inteirados, que, obrigados ao silêncio, forçava a mentiras formais". (MANN, 1979, p. 149). Ao gerente do hotel perguntou o motivo da desinfecção de Veneza e ouviu: "Trata-se [...] de uma medida tomada pela polícia, determinada a prevenir, devidamente e a tempo, uma série de nocividades ou incômodos à saúde geral, que podiam ser germinados pelo calor intenso". (MANN, 1979, p. 150). Durante uma apresentação musical no mesmo local, Aschenbach questionou um artista sobre o assunto que ficou surpreso com o estrangeiro:

- Por causa da polícia! É regulamento, meu senhor, neste calor e com siroco. O siroco comprime. Não faz bem à saúde...

Falava como se estivesse admirado de alguém perguntar coisa semelhante e demonstrava, com a palma da mão, quanto o siroco comprimia

- Então não há mal nenhum em Veneza? - perguntou Aschenbach muito baixo e entre dentes. [...]

- Um mal? Mas que mal? Será nossa polícia um mal? O senhor graceja! Um mal? Esta agora! Uma medida preventiva, compreende, meu senhor? Uma disposição repentina contra os efeitos da atmosfera sufocante... (MANN, 1979, p. 154).

Em uma agência inglesa de viagens, localizada na Praça de São Marcos, Aschenbach trocou dinheiro e fez a pergunta fatal a um funcionário que tentou tranquilizá-lo, mas um estrangeiro de olhos azuis desdenhou a "declaração oficial" que visava proteger a indústria do turismo e alertou:

[...] o medo de prejuízos gerais, a consideração com a recente abertura da exposição de pintura nos jardins públicos, as enormes baixas que ameaçavam os hotéis, as lojas, toda a múltipla indústria turística, nos casos de pânico e difamação, mostrava-se mais forte na cidade que o amor à verdade e o respeito a acordos internacionais, possibilitando às autoridades sus- 
tentarem tenazmente sua política de ocultar e negar. O chefe do Departamento de Saúde, um homem íntegro, renunciara, revoltado, ao seu posto, e fora substituído imediatamente por uma pessoa mais submissa (MANN, 1979, p. 158 e 159).

O perigo, a insegurança, as artimanhas e a corrupção das autoridades eram do conhecimento público e provocou: "uma certa indecorosidade das camadas inferiores, um encorajar de instintos obscuros e anti-sociais que se manifestavam por intemperança, descaramento e crescente criminalidade". Fato é que:

[...] Contra as normas, encontravam-se, à noite, muitos bêbados; gentalha maligna, diziam, fazia as ruas inseguras à noite; ataques de ladrões, e mesmo assassinatos, se repetiam, pois, já por duas vezes, fora comprovado que supostas vítimas da epidemia haviam sido envenenadas por parentes; e o meretrício tomou formas importunas e devassas, como até então não fora conhecido aqui, somente sendo encontrado no sul do país e no Oriente (MANN, 1979, p. 159).

Diante da explanação detalhada dos perigos frente a epidemia que se alastrava, o inglês aconselhou Aschenbach a partir imediatamente, mas não foi ouvido: "Numa excitação febril, triunfante na posse da verdade, sentindo um gosto de nojo na boca e um pavor fantástico no coração, o solitário [...] cogitou de um ato purificante e decente" (MANN, 1979, p. 159): avisar a mãe de Tadzio que Veneza estaria infeccionada e de que ela e prole deveriam fugir do pântano, mas nada fez. Ele teve um pesadelo: "Vapores comprimiam o cérebro, o cheiro penetrante dos bodes, a atmosfera de corpos arquejantes e um sopro das águas pútridas, e além deste ainda um outro, familiar: de feridas e doença propagada" (MANN, 1979, p. 162).

\section{A transmissăo da enfermidade por morangos velhos em Aschenbach}

Apesar das imagens sonhadas de uma paisagem terrível e da constatação da partida de inúmeros turistas, o escritor somente se preocupava com a sua aparência diante da beleza do meni- 
no: "À vista da doce juventude que o enfeitiçara, sentia nojo de seu corpo envelhecido; o aspecto de seus cabelos grisalhos e seus traços marcados faziam-no sentir vergonha e desespero" (MANN, 1979, p. 163) e, por isso, foi ver o barbeiro do hotel que the tingiu os cabelos e maquiou a pele do rosto:

Aschenbach, descansando confortavelmente, incapaz de uma reação, ao contrário, excitado esperançosamente pelo que se passava, viu no espelho suas sobrancelhas arquearem-se mais decisivas e simétricas, o corte de seus olhos prolongar-se, o brilho deles aumentar com uma ligeira pintura da pálpebra, viu mais abaixo, onde a pele fora de um moreno encorreado, com uma aplicação suave, aparecer um carmim delicado, seus lábios anêmicos, ainda há pouco, avolumarem-se cor de framboesa, as rugas das faces, da boca, dos olhos, desaparecerem sob creme e sopro de juventude - avistou, com o coração palpitando, um jovem florescente. [...]

O deslumbrado saiu, feliz como num sonho, desconcertado e medroso. Sua gravata era vermelha, seu chapéu de palha de aba carga era circundado por uma fita multicolorida (MANN, 1979, p. 164 e 165).

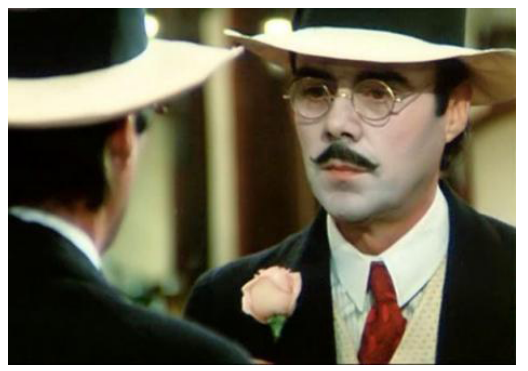

Fig. 2 - Gustav Aschenbach (Dirk Bogarde) Morte em Veneza (1971), filme de Luchino Visconti

Satisfeito com sua nova aparência, Aschenbach saiu e percebeu que um vento "morno de tempestade aparecera; chovia pouco e raras vezes, mas o ar estava úmido, pesado e repleto de vapores pútridos [...] o mormaço tirava o apetite e a ideia se impingia de que os alimentos estivessem envenenados por males contagiosos". Atrás das "pegadas do belo", que passeava com a família rumo a uma arqueada ponte, o escritor perdeu de vista to- 
dos, "no interior da cidade doente", enquanto começou a se sentir mal: a cabeça ardia, o corpo estava suado e a nuca tremia. Como a sede era terrível, ele comprou morangos, "mercadoria passada e mole", sentou-se nas escadas de uma pequena praça abandonada, com capim entre as pedras e lixo, e sentiu que "Lufadas de vento morno traziam de vez em quando o cheiro de ácido fênico" (MANN, 1979, p. 165 e 166).

Dias mais tarde, adoentado, com vertigens e medo, o escritor soube que a família de Tadzio iria partir, depois do almoço. Aflito foi para a praia, sentou-se em uma cadeira espreguiçadeira e avistou o menino lutando com o colega Jachu, que, ajoelhado nas costas dele, apertou seu rosto na areia, quase o sufocando. Aschenbach quis se levantar no momento em que o agressor soltava sua vítima, que se afastou rumo ao mar, parou e se virou em direção do escritor: "pareceu-Ihe que o pálido e gracioso psicagogo lá fora Ihe sorria, Ihe acenava, como se, soltando as mãos dos quadris, apontasse para fora, flutuando na sua frente para a imensidão auspiciosa. E, como tantas vezes, levantou-se para segui-Io" (MANN, 1979, p. 170).

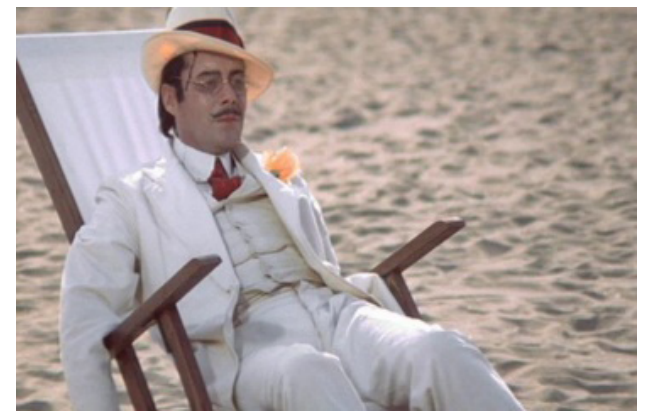

Fig. 3 - Aschenbach, moribundo, observa Tadzio, filme (1971)

Exausto, suando muito e com a tinta do cabelo a escorrer pelo rosto, o escritor não conseguiu se erguer: "Minutos passaram até virem em auxílio do que caíra de lado na cadeira. Levaram-no para o seu quarto. E, ainda no mesmo dia, um mundo respeitosamente comovido recebeu a notícia de sua morte" (MANN, 1979, p. 170).

Em Morte em Veneza: desejo e interdição, José Miguel Rasia enfatiza que: "Aschenbach não poderia sobreviver à partida de Tadzio, pois: " Aquele que parte leva consigo a vida, desfazendo a alian- 
ça narcísica imaginarizada até o enlouquecimento por Aschenbach. Nesse momento, como é anunciado durante toda a novela, triunfava silenciosa e sorrateira a pulsão de morte" (RASIA, 2001, p. 76).

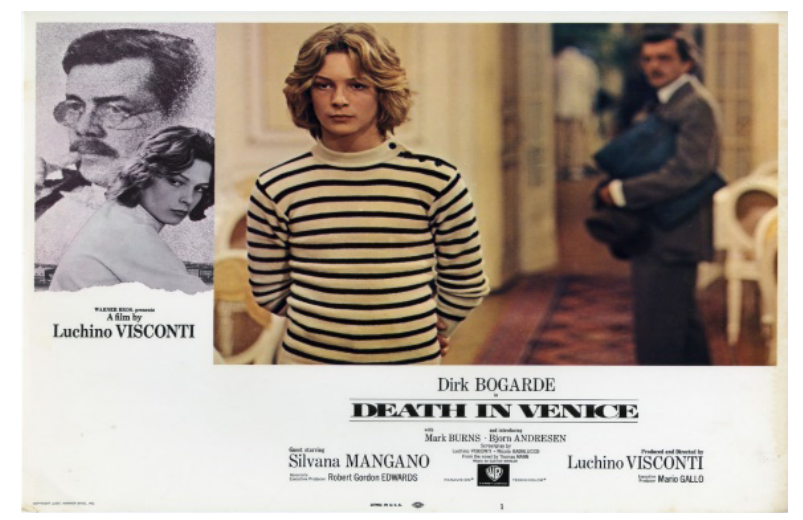

Fig. 4- Tadziu (Bjorn Andresen), cartaz do filme

No filme de Luchino Visconti, baseado na novela homônima de Thomas Mann, o escritor é transformado em um músico, em alusão a Gustav Mahler, que foi o modelo para a elaboração do protagonista, segundo Mann. Além disso, a narrativa visual inicia-se com a viagem de Aschenbach, a caminho de Veneza, em um barco a vapor, enquanto que na novela original, a obra tem princípio com a vida dele em Munique. Aos sons do Adagietto, de Mahler, na praia do Lido, falece o escritor, de acordo com Arthur Nestrovski em Morte e Veneza (NESTROVSKI, 1996, p. 90).

\section{Conclusằo}

O estudo, "A epidemia do cólera em $A$ morte em Veneza (1911-1912), de Thomas Mann (1875-1955)", revelou que a narrativa apresenta um tratado sobre o fazer artístico em diálogo com o conceito de Nietzsche sobre o ser apolíneo e o dionisíaco: a tensão entre a razão (Apolo), personificada por Aschenbach, adepto da beleza harmoniosa e comedida, e a desmedida (Dionísio), presente na beleza de Tadzio, que o leva a contemplar o Belo (platonismo). A visão de tal beleza, como forma de elevar o espírito ao estado mais puro do ser humano, o impacta de tal forma que o escritor permanece na cidade sinistra, embora soubesse da periculosidade do cólera. 
O título da narrativa anuncia uma morte, um leitmotiv revelado em três momentos primeiro, por mensageiros fúnebres - 0 estranho ruivo na capela do Cemitério Norte de Munique; o vendedor de passagens do barco a vapor Pula-Veneza e o gondoleiro ilegal, como um tipo de Caronte, o barqueiro de Hades, responsável pela travessia das almas -; segundo, pela bela e dionisíaca paisagem da cidade, que oculta outra paisagem tenebrosa, e terceiro, a paisagem da enfermidade mortal, transmitida por diversos tipos de alimentos, e presente nas águas pútridas e malcheirosas.

A análise, baseada nos conceitos de 'lugar concreto' e de 'espaço abstrato', de Tuan, enfatizou a experiência humana, social, cultural e existencial em diferentes paisagens venezianas: um lugar real, que evoca um espaço abstrato, nos quais, as experiências de Gustav Aschenbach, individuais e coletivas, destacam-se por meio dos "sentidos mais diretos e passivos como o olfato, paladar e tato, até a percepção visual ativa e a maneira indireta de simbolização". (TUAN, 2013, p. 17). Veneza para ele representa o renascimento para a vida e para a morte.

Thomas Mann revela-se um escritor crítico, que, aos 36 anos de idade, denuncia em sua novela, as irresponsáveis artimanhas das autoridades de Veneza, para ocultar a epidemia, colocando em risco a vida de tantas pessoas.

\section{Referências}

BAHR, E. Thomas Mann. Der Tod in Venedig. Stuttgart: Philipp Reclam, 1991.

MANN, T. A Morte em Veneza. In: MANN, Thomas. Tônio Kroeger. A morte em Veneza. Trad. de Maria Deling. São Paulo: Abril Cultural, 1979. p. 87-170.

MORENO CLAROS, L. F. $O$ último amor de Goethe. 21 mar. 2008. Disponível em: http://www.blogletras.com/2008/03/o-ultimo-amor-de-goethe.html. Acesso em: 12 jul. 2021.

NESTROVSKI, A. Morte em Veneza. In: NESTROVSKI, A. Ironias da Modernidade: Ensaios sobre Literatura e Música. São Paulo: Ática, 1996. p. 90-94.

RASIA, J. M. Morte em Veneza: desejo e interdição. Revista Letras, Curitiba, n. 55, p. 55-77, jan./jun., 2001.

ROSENFELD, A. Thomas Mann. São Paulo: Perspectiva/EDUSP; Campinas: Editora Unicamp, 1994. 
VENEZA. Disponível em: https://pt.wikipedia.org/wiki/Veneza. Acesso em: 12 jul. 2021.

V.K. Paisagens de Bad Tölz podem ser inspiradoras: Um famoso escritor alemão aproveitou as temporadas na cidade para escrever um clássico. $\mathbf{O}$ Estado de $\mathbf{S}$. Paulo, 28 mai. 2002, Viagem Alemanha, p. V10.

\section{Iconografia}

Fig. 1 - Hotel dos Banhos (Hotel des Baines), em Veneza. Disponível em: https://www.tripadvisor.pt/Attraction_Review-g3547567-d10832383-Reviews-Hotel_des_Bains-Lido_di_Venezia_Veneto.html\#/media-atf/10832383/423324329:p/?albumid=-160\& type=0\&category=-160. Acesso em: 12 jul. 2021.

Fig. 2 - Gustav Aschenbach (Dirk Bogarde). Morte em Veneza (1971), filme de Luchino Visconti. Disponível em: https://cinemaemcena.com.br/coluna/ ler/485/morte-em-veneza. Acesso em: 12 jul. 2021.

Fig. 3 - Aschenbach, moribundo, observa Tadzio, filme (1971). Disponível em: https://estadodaarte.estadao.com.br/visconti-e-mahler-muito-alem-do-adagietto. Acesso em: 12 jul. 2021.

Fig. 4 - Tadzio (Bjorn Andresen), cartaz do filme. Disponível em: https://olivre. com.br/ver-o-livro-ler-o-filme-cine-teatro-cuiaba-exibe-morte-em-veneza-nessa-quarta-feira. Acesso em: 12 jul. 2021. 